\title{
Impactos do Crédito sobre Crescimento Econômico dos Municípios do Espírito Santo: Análises para o Período de 2005 a 2015
}

Impacts of Credit on Economic Growth of the Municipalities of Espírito Santo: An Analysis for the Period from 2005 to 2015

\author{
Edson Zambon Monte \\ Bruna Bergamin Aguiar ${ }^{\mathrm{b}}$ \\ Renzo Caliman Souzac
}

\begin{abstract}
Resumo: Este trabalho objetivou analisar os efeitos do crédito sobre crescimento econômico dos municípios do Espírito Santo, no período de 2005 a 2015, utilizando a metodologia de danos em painel. As análises foram feitas considerando o Produto Interno Bruto total (PIB total) e o PIB dos setores: agropecuário, industrial e comercial e de serviços. Os resultados revelaram que a oferta de crédito contribuiu para o crescimento econômico dos municípios do Espírito Santo. Portanto, políticas públicas que facilitem a tomada de crédito podem levar a bons resultados econômicos para os municípios capixabas.
\end{abstract}

Palavras-chave: Crescimento Econômico; Crédito; Análise Setorial; Espírito Santo. Classificação JEL: G21; O16; R11; C33.

\begin{abstract}
The aim of this study was to analyze the effects of credit on economic growth of the municipalities of Espírito Santo, from 2005 to 2015, using panel data methodology. The analysis was performed considering the total Gross Domestic Product (total GDP) and the GDP of the following sectors: agricultural, industrial, commercial and services. The results showed that credit supply contributed to the economic growth of the municipalities of Espírito Santo. Therefore, public policies that facilitate credit can lead to good economic results for the municipalities of Espírito Santo.
\end{abstract}

Keywords: Economic Growth; Credit; Sectorial Analysis; Espírito Santo.

JEL Classification: G21; O16; R11; C33.

\footnotetext{
a Professor do Departamento de Economia e Membro do Grupo de Pesquisa em Econometria (GPE), da Universidade Federal do Espírito Santo (UFES). E-mail: edsonzambon@yahoo.com.br.

${ }^{\mathrm{b}}$ Economista pela Universidade Federal do Espírito Santo (UFES). E-mail: bruberaguiar@ hotmail.com.

${ }^{\text {c }}$ Mestrando em Economia pela Universidade Federal do Espírito Santo (PPGEco/UFES), bolsista FAPES. Membro do Grupo de Pesquisa em Econometria (GPE/UFES). E-mail: renzo.caliman@ hotmail.com.
} 


\section{Introdução}

O debate na teoria econômica sobre a relação entre o desenvolvimento financeiro e o crescimento econômico não é recente, e ganhou nova força a partir da década de 1990, com os trabalhos de King e Levine (1993a, 1993b). Seguindo esta linha de pensamento, diversos trabalhos, teóricos e empíricos, tentaram demonstrar a hipótese de que o desenvolvimento financeiro afeta diretamente o crescimento econômico, a saber: Goldsmith (1969); McKinnon (1973); Shaw (1973); Bencivenga e Smith (1991); SaintPaul (1992); King e Levine (1993a, 1993b); Roubini e Sala-i-Martin (1992); Pagano (1993); Bencivenga, Smith e Starr (1996); Blackburn e Hung (1998); e, Deidda (2006). Destaca-se que, segundo Jacques e Gonçalves (2016), observando por um lado não muito convencional, as abordagens contemporâneas sobre o tema em geral remetem-se aos trabalhos de Schumpeter (1911) e de Keynes (1936). ${ }^{1}$

Vale dizer que a ideia de que há um relacionamento unidirecional do desenvolvimento financeiro para com o crescimento econômico não é consenso na literatura. De acordo com Greenwood e Jovanovic (1990), existe uma determinação conjunta no que diz respeito ao desenvolvimento do sistema financeiro e ao crescimento econômico, ou seja, a relação é bidirecional. Ainda, pode-se caracterizar uma terceira linha de pensamento, baseada no trabalho de Modigliani e Miller (1958). Os autores salientam que a forma de financiamento das empresas é irrelevante, indo ao encontro de que os mercados financeiros são agentes independentes do resto da economia e, por consequência, financiamento e crescimento são não correlacionados.

No que se refere à economia brasileira, diversos trabalhos demonstraram uma causalidade unidirecional positiva entre o desenvolvimento financeiro e o crescimento econômico, seja em nível nacional ou estadual, por exemplo: Matos (2002); Romero e Ávila (2010); Missio, Jayme Jr e Oliveira (2015); entre outros. Em contrapartida, Reichstul e Lima (2006), em estudo para a Região Metropolitana de São Paulo (RMSP), encontraram uma causalidade bidirecional (no sentido causa Granger) entre a atividade financeira e o crescimento econômico. Já Zara (2006), em estudo para os estados brasileiros, não encontrou significância estatística entre o crédito estadual e o crescimento econômico.

Assim, tanto em nível teórico quanto em nível aplicado, não existe uma clara direção no que diz respeito à causalidade entre as duas variáveis, seja em nível internacional ou nacional. Para Lawrence (2006), os resultados empíricos parecem aprofundar a dicotomia existente, em função da ambiguidade dos mesmos. No entanto, conforme descrito por Reichstul e Lima (2006), mesmo havendo divergências, parece haver, na literatura econômica, certo consenso no que se refere ao desenvolvimento financeiro impactar positivamente o nível de atividade econômica. Neste caso, a oferta de crédito, desde que

\footnotetext{
${ }^{1}$ Drummond e Aguiar (2004) trazem três excelentes descrições em seu estudo, a saber: i) classificam e explicam as funções do sistema financeiro e os canais de influência sobre o crescimento econômico; ii) apresentam alguns modelos teóricos de crescimento endógeno que incorporam explicitamente o sistema financeiro; e, iii) descrevem alguns estudos que testam empiricamente a possível relação existente entre o desenvolvimento do setor financeiro e o crescimento econômico.
} 
trabalhada adequadamente em termos de prazo, custos e quantidades, pode levar à concretização de oportunidades de investimentos ex ante.

Este trabalho, partindo da hipótese de que as operações de crédito influenciam o crescimento econômico, buscou analisar os efeitos do crédito sobre crescimento econômico dos municípios do Espírito Santo, no período de 2005 a 2015, de forma agregada (PIB total) e segmentada por setores: agropecuário (PIB agropecuário), industrial (PIB industrial) e comercial e de serviços (PIB comércio e serviços). Ressalte-se que, Dow (1982) e Amado (1997), ao caracterizarem as regiões periféricas, descrevem que nas mesmas predominam o setor terciário e a agricultura. Para Caçador e Grassi (2009), o Espírito Santo pode ser considerado um estado periférico no contexto regional brasileiro. Entretanto, nos municípios do Espírito Santo predomina o setor terciário, sendo esse alavancado pela administração pública e pelo comércio. Em seguida, tem-se o setor industrial (secundário), prevalecendo a extração mineral (minério de ferro, petróleo e gás). Por último está a agricultura, com a cafeicultura como uma das atividades mais importantes. Logo, a principal contribuição desta pesquisa está na avaliação empírica dos impactos do crédito sobre a atividade econômica dos municípios capixabas, sob uma perspectiva local de um estado periférico, em que os setores terciário e industrial são os mais relevantes.

Cabe dizer que, no que tange ao estado do Espírito Santo, Caçador e Monte (2012) verificaram o papel do crédito no crescimento econômico dos municípios do Espírito Santo, utilizando-se a técnica de dados em painel, para o período de 2001 a 2008, considerado 66 municípios (de um total de 78). Para o período e os municípios considerados, os autores verificaram fortes impactos na variação do crescimento dos municípios capixabas em resposta a alterações no crédito.

Esta pesquisa avança nos seguintes pontos em relação ao estudo de Caçador e Monte (2012): i) o período de abrangência foi de 2005 a 2015; ii) considerou-se os 78 municípios do Espírito Santo; iii) utilização de indicadores socioeconômicos e demográficos como variáveis de controle nas estimativas realizadas; e, iv) além das estimativas para o total de municípios (78), as estimações foram realizadas para duas subamostras. Neste caso, nove municípios do Espírito Santo (Cachoeiro de Itapemirim, Cariacica, Colatina, Guarapari, Linhares, São Mateus, Serra, Vila Velha e Vitória) concentraram 72,31\% do volume de crédito ofertado no estado, em 2015, sendo que estes municípios possuíam mais de $100 \mathrm{mil}$ habitantes. Os outros 69 munícipios respondiam por, somente, 27,69\% da oferta de crédito, no ano de 2015. Logo, para complementar e dar robustez às análises, além das regressões para todos os municípios, estimativas foram feitas para dois blocos de municípios: a) municípios com maior volume de crédito (mais de 100 mil habitantes); e, b) municípios com menor volume de crédito (menos de 100 mil habitantes). A ideia foi verificar se existem diferenças significativas destes dois conjuntos de municípios quando comparado com as estimações para os 78 municípios, no que se refere aos impactos da oferta de crédito sobre o crescimento econômico. Os resultados vistos à frente evidenciam um elevado efeito positivo da oferta de crédito sobre a variação do PIB (total, industrial, comercial e de serviços e agropecuário) dos municípios capixabas. 
O presente artigo está estruturado da seguinte forma. Além desta introdução, a seção 2 traz uma breve revisão de literatura empírica. Na seção 3 são descritas as variáveis e o referencial analítico; dados em painel. As análises estatísticas/econométricas são demonstradas na seção 4. Por fim, as considerações finais são apresentadas na seção 5.

\section{Revisão de Literatura Empírica}

Esta seção traz uma breve revisão de literatura de trabalhos que estudaram a relação entre financiamento e crescimento, uma vez que, conforme já descrito, os resultados empíricos parecem aprofundar a dicotomia existente na relação tais variáveis econômicas (LAWRENCE, 2006). A ideia aqui não é seguir somente uma vertente de pesquisa, mais dar um panorama geral das pesquisas que relacionam crédito e crescimento, independentemente dos resultados encontrados. A primeira parte apresenta alguns estudos da literatura internacional e, a segunda parte, pesquisas relacionadas ao Brasil, sejam em nível nacional ou regional.

Um dos trabalhos mais relevantes no plano internacional, no que se refere ao desenvolvimento financeiro, é o de King e Levine (1993a). Os autores, em pesquisa para 80 países, compreendendo o período de 1960 a 1989, verificaram que várias medidas do nível de desenvolvimento financeiro são correlacionadas com o crescimento do PIB real per capita, a taxa de acumulação de capital físico, e as melhorias na eficiência com que a economia emprega o capital físico. No mais, o componente predeterminado do desenvolvimento financeiro está altamente correlacionado com as taxas futuras de crescimento econômico, a acumulação de capital físico e as melhorias de eficiência econômica.

Demetriades e Hussein (1996), em um estudo de séries temporais para 16 países, realizaram testes de causalidade entre o desenvolvimento financeiro e o PIB real. Os resultados revelaram pouco apoio à visão de que o financiamento é um setor líder no processo de desenvolvimento econômico. No entanto, foram encontradas evidências consideráveis de bidirecionalidade e algumas evidências de causalidade reversa entre as variáveis. Além disso, contatou-se que os padrões de causalidade variam entre os países, levando os autores a destacarem os perigos da inferência estatística com base em estudos transversais de países que implicitamente tratam diferentes economias como entidades homogêneas.

Levine e Zervos (1998) analisaram se o bom funcionamento do mercado de ações e dos bancos promove o crescimento econômico de longo prazo, considerando um máximo de 47 países, no período de 1973 a 1993. Os resultados demonstraram que a liquidez do mercado acionário e o desenvolvimento bancário preveem positivamente o crescimento, a acumulação de capital e as melhorias de produtividade, mesmo após o controle de fatores econômicos e políticos. Os resultados são consistentes com a ideia de que os mercados financeiros fornecem serviços importantes que estimulam o crescimento.

Levine (1999) analisou como fatores exógenos - por exemplo, características dos ambientes legais e de regulação - afetam o desenvolvimento financeiro, e como este fator 
está vinculado ao crescimento econômico de longo prazo. Segundo o autor, os resultados revelaram que tais componentes estão positivamente associados ao crescimento econômico. Isto é, os resultados são consistentes com a visão de que as mudanças legais e regulatórias que impulsionam o desenvolvimento dos intermediários financeiros induzirão a uma rápida aceleração no crescimento econômico de longo prazo.

Asteriou e Price (2000) investigaram os efeitos do desenvolvimento financeiro e do mercado de ações no processo de crescimento econômico do Reino Unido, por meio de duas hipóteses: i) o sistema financeiro é seguidor da demanda de recursos financeiros, logo o desenvolvimento financeiro não afeta o crescimento econômico; e, ii) o sistema financeiro seria condutor da oferta e, assim, o desenvolvimento do setor financeiro afeta o crescimento da economia. Usando testes de cointegração e causalidade, os autores concluíram que há fortes evidências de que o setor financeiro é condutor da oferta de recursos, ou seja, as direções causais vão do desenvolvimento financeiro para o setor real da economia.

Guiso, Sapienza e Zingales (2004) estudaram os efeitos das diferenças de desenvolvimento financeiro local dentro de um mercado financeiro integrado, para a economia italiana. Para isso, os autores construíram um novo indicador de desenvolvimento financeiro, estimando um efeito regional sobre a probabilidade de que, ceteris paribus, uma família esteja desligada do mercado de crédito. Por meio desse indicador, constatou-se que o desenvolvimento financeiro eleva a probabilidade de um indivíduo começar seu próprio negócio, e favorece a entrada, aumenta a concorrência e promove o crescimento das empresas. No entanto, esses efeitos são mais fracos para empresas maiores, que podem mais facilmente levantar fundos fora da área local. No geral, os resultados sugerem que o desenvolvimento financeiro local é um determinante importante do sucesso econômico de uma região, mesmo em um ambiente em que não há atritos com os movimentos de capital.

Önder e Özyildirim (2009) estudaram o impacto do crédito para o crescimento regional, na Turquia, onde os bancos estatais têm um papel implícito de reduzir a disparidade, alocando empréstimos em regiões subdesenvolvidas que são ignoradas pelos bancos privados. Os resultados sugeriram um efeito paradoxal dos bancos estatais no desenvolvimento regional, pois os financiamentos realizados pelos mesmos não estimularam o bem-estar das regiões menos desenvolvidas, mas sim, contribuíram significativamente para o crescimento de locais mais desenvolvidas. Por outro lado, os créditos fornecidos por bancos privados, em geral, impactam positivamente o PIB real per capita em ambas as regiões, desenvolvidas e menos desenvolvidas.

Hassan, Sanchez e Yu (2011) verificaram a relação entre desenvolvimento financeiro e crescimento econômico, em países de baixa e média renda, por meio de regressões de dados em painel e de decomposições de variação das taxas de crescimento anual do PIB. De forma mais específica, o intuito foi examinar quais medidas indiretas de desenvolvimento financeiro são mais importantes para explicar o crescimento econômico ao longo do tempo e o quanto elas contribuem para explicar o crescimento entre regiões geográficas e grupos de renda. Os resultados mostram uma relação positiva entre o 
desenvolvimento financeiro e o crescimento econômico nos países em desenvolvimento. Além disso, a análise multivariada de curto prazo forneceu os seguintes resultados: i) uma relação de causalidade bidirecional entre financiamento e crescimento para a maioria das regiões; e, ii) uma causalidade unidirecional do crescimento para o financiamento para as duas regiões mais pobres. Além disso, outras variáveis do setor real, como comércio e gastos do governo, desempenham um papel importante na explicação do crescimento econômico. Dessa forma, os autores concluíram que um sistema financeiro que funcione bem parece ser uma condição necessária, mas não suficiente, para alcançar um crescimento econômico estável nos países em desenvolvimento.

Conforme já descrito, no caso brasileiro, diversos trabalhos tentaram mensurar as relações entre financiamento e crescimento econômico. Monte e Távora Júnior (2000), por exemplo, estudaram o impacto dos financiamentos regionais advindos do Fundo Constitucional de Financiamento do Nordeste-FNE (Banco do Nordeste), do Fundo de Investimento do Nordeste-Finor (Sudene) e do Banco Nacional de Desenvolvimento Econômico e Social (BNDES) sobre produto regional (Região do Nordeste). Os autores adotaram a metodologia de dados em painel, considerando os períodos de 1981-1995 (Finor), 1998-1998 (FNE) e 1981-1995 (recursos do BNDES). Mesmo não tendo sido inseridas variáveis de controle nas equações estimadas, os resultados obtidos para o PIB total e setoriais revelaram forte relação positiva, sugerindo a relevância de tais fontes de recursos para o crescimento econômico regional.

Matos (2002) avaliou a relação entre o desenvolvimento o financeiro e o crescimento econômico no Brasil. Como metodologia, os autores adotaram o teste de causalidade proposto Granger, e consideraram os períodos 1947-2000, 1963-2000 e 1970-2000. Os resultados obtidos dão suporte empírico à existência de impactos diretos e unidirecionais do desenvolvimento financeiro sobre o crescimento econômico, quando são utilizadas, para isso, as razões crédito bancário ao setor privado/PIB, crédito do sistema financeiro ao setor privado/PIB e recursos do público confiados ao sistema financeiro/M2, como indicadores do desenvolvimento financeiro.

Marques Jr. e Porto Jr. (2004) verificaram a relação de causalidade entre desenvolvimento financeiro (DF) e crescimento econômico (CE), no Brasil, o período de 1950 a 2000. Para isso, construíram três conjuntos de indicadores proxies para o desenvolvimento do sistema bancário e para o mercado de capitais do Brasil. No mais, os autores realizaram um teste de Causalidade de Granger clássico para a relação entre CE e DF, nas séries estacionárias. Para as variáveis não estacionárias, procedeu-se um teste de cointegração de Johansen e, posteriormente, um teste de causalidade baseado no modelo de Demetriades e Hussein (1966). Concluiu-se que a relação de causalidade é inequívoca no sentido de que DF causa CE quando os indicadores são de desenvolvimento do sistema bancário. Quando a relação de causalidade é aplicada aos indicadores de desenvolvimento do mercado de capitais, a conclusão é contraditória. Porém, há maior robustez para a causalidade no sentido de DF para CE, nesse último caso.

Reichstul e Lima (2006) contribuíram para o entendimento da causalidade entre crédito bancário e atividade econômica, em estudo para a Região Metropolitana de São 
Paulo (RMSP). A pesquisa analisou a relação entre diferentes modalidades de crédito bancário e um indicador de atividade econômica na RMSP entre janeiro de $1992 \mathrm{e}$ dezembro de 2003. Por meio de um modelo bivariado de vetores autorregressivos, os autores detectaram uma causalidade bidirecional entre crédito e nível de atividade econômica.

Kroth e Dias (2006) verificaram como o crédito bancário e o capital humano afetaram o crescimento econômico dos municípios brasileiros, no período entre 1999 a 2003. Os autores adotaram o método de dados em painel dinâmico. Os resultados revelaram a existência de uma causalidade no sentido de operações de crédito e do capital humano sobre o crescimento econômico dos municípios no período analisado.

Rocha e Nakane (2007), utilizando dados em painel, estudaram a direção da causalidade entre desenvolvimento econômico e alguns indicadores financeiros selecionados para os estados do Brasil. Para tanto, os autores usaram de um procedimento de teste baseado nas metodologias sugeridas por Holtz-Eakin, Newey e Rosen (1988) e Granger e Huang (1997). Os principais resultados foram: i) parece haver evidência de que os indicadores financeiros utilizados Granger-causaram o produto; e, existiram evidências de que a causalidade em sentido contrário, ou seja, o produto Granger-causa o sistema financeiro, aparece quando utilizada uma base de dados mensal. Conforme Rocha e Nakane (2007), essa inversão de resultados pode ser devido à natureza de longo prazo dos fenômenos por trás da relação entre sistema financeiro e produto.

Romero e Ávila (2010) estudaram a interação entre as esferas financeira e produtiva. Foram discutidas as características do sistema financeiro brasileiro e examinada a evolução do financiamento bancário da atividade industrial por região. Buscou-se, ainda, ressaltar a importância da atuação dos bancos para o desenvolvimento. Foi desenvolvida uma análise multivariada que indicou a existência de correlação espacial entre as variáveis financeiras e o emprego industrial. Também foi estimado um modelo para dados em painel para os estados brasileiros, o qual demonstrou a existência de impactos distintos das variáveis financeiras sobre o nível de emprego nos setores industriais analisados.

Missio, Jayme Jr e Oliveira (2015) objetivaram analisar, teórica e empiricamente, a relação entre o desenvolvimento financeiro e o crescimento econômico para as unidades federativas do Brasil. Como metodologia, o trabalho adotou a técnica de regressão quantílica, para o período de 1995 a 2004. Os autores seguiram duas abordagens para mensurar o desenvolvimento do sistema financeiro, baseadas na construção de indicadores que captam dimensões como o tamanho do setor, o nível de atividade, o desenvolvimento e a eficiência do sistema financeiro. No mais, a análise empregou um indicador da preferência pela liquidez do público e dos bancos para captar o argumento da teoria póskeynesiana. Os resultados revelaram que, em geral, houve uma relação positiva entre desenvolvimento do sistema financeiro e crescimento econômico e a possibilidade de efeitos regionais distintos.

Como pode ser observado, com algumas exceções, a maior parte dos trabalhos, seja em nível internacional ou nacional, demonstra haver efeitos positivos do crédito sobre o crescimento econômico. Esta pesquisa visou contribuir para as discussões da área, 
analisando se, para uma economia local, periférica, em que os setores terciário e industrial são os mais relevantes, a oferta de crédito tem impactos positivos e significativos sobre o crescimento, controlando para indicadores socioeconômicos e demográficos.

\section{Metodologia}

\subsection{Apresentação das Variáveis}

Os dados utilizados neste trabalho são do tipo dados em painel. As variáveis são apresentadas na Tabela 1. A análise foi realizada para os 78 municípios do Espírito Santo, considerando o período de 2005 a 2015 (frequência anual). No que tange ao crescimento econômico, seguindo a prática mais comum na literatura (GELB (1989); ROUBINI; SALA-I-MARTIN (1992); KING; LEVINE (1993a, 1993b); MATTOS (2002)), adotou-se como medida o Produto Interno Bruto (PIB) total ou desagregado por setor, disponibilizados pelo Instituto Brasileiro de Geografia e Estatística (IBGE). Foram estimadas várias regressões onde o PIBTOTAL, o PIBAGRO, o PIBIND e o PIBSERV entraram como variável resposta.

No que tange à variável de tratamento operações de crédito (OPCRED) ${ }^{2}$, ressalta-se que a mesma representa o estoque total das operações de empréstimos e financiamentos concedidos pelas instituições integrantes do Sistema Financeiro Nacional (SFN), e que estejam localizadas nos municípios do Estado do Espírito Santo. Os dados foram provenientes do subsistema ESTBAN (Estatística Bancária) do Banco Central do Brasil (BACEN), que reflete a posição mensal dos saldos das principais rubricas de balancetes dos bancos comerciais e dos bancos múltiplos com carteira comercial. A fim de representar os saldos anuais com operações de crédito dos municípios foi utilizado o saldo anual ao final do mês de dezembro do respectivo ano (por exemplo: o saldo do ano de 2015 referese ao saldo anual ao final do mês de dezembro de 2015).

No mais, com o intuito de dar mais robustez às estimativas, indicadores socioeconômicos e demográficos foram adotados como variáveis de controle. Para tanto, adotou-se a variável POP, coletada do IBGE e, como proxies para os indicadores socioeconômicos, as variáveis IFDMGERAL, IFDMEMPR, IFDMEDUC e IFDMSAUDE da Federação das Indústrias do Estado do Rio de Janeiro (FIRJAN) ${ }^{3}$. No mais, utilizou-se entre as variáveis de controle uma variável DUMMY, que recebeu valor um, para o ano de 2009 e, zero, caso contrário, uma vez que o maior impacto negativo da crise do subprime

\footnotetext{
2 Detalhadamente a variável OPCRED engloba: empréstimos e títulos descontados, financiamentos, financiamentos rurais à agricultura (investimento e custeio), financiamentos rurais à pecuária (investimento $\mathrm{e}$ custeio), financiamentos rurais à agricultura (comercialização), financiamentos rurais à pecuária (comercialização), financiamentos agroindustriais, financiamentos imobiliários, outras operações de crédito, outros créditos, crédito em liquidação, provisão para operações de crédito e operações especiais.

3 “O IFDM - Índice FIRJAN de Desenvolvimento Municipal - é um estudo do Sistema FIRJAN que acompanha anualmente o desenvolvimento socioeconômico de todos os mais de cinco mil municípios brasileiros em três áreas de atuação: Emprego \& renda, Educação e Saúde (https://www.firjan.com.br/ifdm/)."
} 
(iniciada nos Estados Unidos em meados de 2007) sobre o crescimento dos municípios ocorreu em 2009. Cabe destacar que a metodologia de dados em painel já permite controlar os efeitos fixos de cada município, sejam observáveis e não observáveis. Assim, é possível controlar o viés causado pela omissão dessas variáveis (ou informações) sobre o coeficiente de interesse.

Tabela 1: Variáveis Utilizadas

\begin{tabular}{l|c|c|c}
\hline \multicolumn{1}{c|}{ Variável } & Sigla & Unidade & Fonte \\
\hline \multicolumn{4}{|c|}{ Variável reposta } \\
\hline PIB total & PIBTOTAL & $\mathrm{R} \$$ mil & IBGE \\
\hline PIB agropecuário & PIBAGRO & $\mathrm{R} \$$ mil & IBGE \\
\hline PIB industrial & PIBIND & $\mathrm{R} \$$ mil & IBGE \\
\hline PIB comercial e de serviços & PIBSERV & $\mathrm{R} \$$ mil & IBGE \\
\hline \multicolumn{4}{c}{ Variável de tratamento } \\
\hline Operações de crédito & OPCRED & $\mathrm{R} \$$ mil & BACEN \\
\hline \multicolumn{4}{|c|}{ Variáveis de controle } \\
\hline População & POP & Número de habitantes & IBGE \\
\hline IFDM geral & IFDMGERAL & Índice & FIRJAN \\
\hline IFDM emprego e renda & IFDMEMPR & Índice & FIRJAN \\
\hline IFDM educação & IFDMEDUC & Índice & FIRJAN \\
\hline IFDM saúde & IFDMSAUDE & Índice & FIRJAN \\
\hline DUMMY & DUMMY & Variável binária & - \\
\hline \hline
\end{tabular}

Fonte: elaborado pelos autores.

Nota: quando necessário, as variáveis foram deflacionadas pelo Índice de Preços ao Consumidor Amplo (IPCA), utilizando 2005 como ano base.

\subsection{Dados em Painel}

A abordagem de dados em painel permite combinar dados de séries temporais com dados de corte transversal (cross-section), estrutura de dados adotada nesta pesquisa. Tomando-se como referência Greene (2012), a forma geral para modelar dados em painel pode ser representada por:

$$
y_{i t}=\boldsymbol{x}_{i t}^{\prime} \boldsymbol{\beta}+\boldsymbol{z}_{i}^{\prime} \boldsymbol{\alpha}+\varepsilon_{i t}, i=1, \ldots, N \text { e } t=1, \ldots, T,
$$

em que existem $K$ regressores em $\boldsymbol{x}_{i t}$, não incluindo o termo constante. A heterogeneidade, ou o efeito individual, é dado por $\boldsymbol{z}_{i} \boldsymbol{\alpha}$, onde $\boldsymbol{z}_{i}$ contém um termo constante e um conjunto de variáveis individuais ou específicas dos grupos, que podem ser observadas, e tomadas como constantes ao longo do tempo $t$. O principal objetivo da análise é estimar de forma consistente e eficiente os efeitos parciais,

$$
\boldsymbol{\beta}=\partial E\left[y_{i t} \mid \boldsymbol{x}_{i t}\right] / \partial \boldsymbol{x}_{i t} .
$$


Se $\boldsymbol{z}_{i}$ é não observado, porém correlacionado com $\boldsymbol{x}_{i t}$, então o estimador de Mínimos Quadrados Ordinários (MQO) de $\boldsymbol{\beta}$ é viesado e inconsistente em função do problema de variáveis omitidas. No entanto, nesses casos, o modelo

$$
y_{i t}=\boldsymbol{x}_{i t}^{\prime} \boldsymbol{\beta}+\alpha_{i}+\varepsilon_{i t}
$$

onde $\alpha_{i}=\mathbf{z}_{i}^{\prime} \boldsymbol{\alpha}$, incorpora todos os efeitos observados e específica uma média condicional estimável. Esta abordagem é denominada de efeitos fixos, em que os $\alpha_{i}$ é um termo constante para cada grupo específico no modelo de regressão. No mais, cada $\alpha_{i}$ é tratado como um parâmetro desconhecido a ser estimado. Neste trabalho, no modelo de efeitos fixos, para diferenciar o intercepto de um indivíduo para o outro, fez-se a utilização de variáveis dummies (least squares dummy variable (LSDV) model). Stock e Watson (2004) salientam que as variáveis binárias refletem todas as variáveis omitidas que diferem de um indivíduo para outro, mas que são constantes ao longo do tempo. Se os erros seguirem distribuição normal, tiverem variância constante (homoscedasticidade) e forem não autocorrelacionados, a Equação (3) pode ser estimada por MQO.

Assumindo que a heterogeneidade individual não observada seja não correlacionada com as variáveis incluídas, $\boldsymbol{x}_{i t}$, então o modelo pode ser formulado como

$$
y_{i t}=\boldsymbol{x}_{i t}^{\prime} \boldsymbol{\beta}+\alpha+u_{i}+\varepsilon_{i t},
$$

isto é, como um modelo de regressão linear com um distúrbio composto, que pode ser consistente, embora ineficientemente, estimado por MQO. Tal abordagem é chamada de efeitos aleatórios, onde existem $K$ regressores incluindo uma constante, sendo que agora o único termo constante é a média da heterogeneidade não observada, $\alpha=E\left[\mathbf{z}_{i}^{\prime} \boldsymbol{\alpha}\right]$. O componente $u_{i}$ é a heterogeneidade aleatória específica para a i-ésima observação e é constante no tempo; tem-se que $u_{i}=\mathbf{z}_{i}^{\prime} \boldsymbol{\alpha}-E\left[\mathbf{z}_{i}^{\prime} \boldsymbol{\alpha}\right]$. Para o modelo de efeitos aleatórios, o método mais adequado é o de Mínimos Quadrados Generalizados (MQG).

\section{Resultados e Discussões}

Esta seção está dividida da seguinte forma: na primeira parte são apresentadas as estatísticas descritivas e uma breve caracterização da oferta de crédito nos municípios do Espírito Santo; e, na segunda, encontram-se as estimativas econométricas.

\subsection{Estatística Descritiva e Oferta de Crédito nos Municípios Capixabas}

A Tabela 2 apresenta as estatísticas descritivas das variáveis, considerando o período de 2005 a 2015 e, também, os 78 municípios do Espírito Santo. Nota-se que a média do PIB total (PIBTOTAL) foi de $\mathrm{R} \$ 852.715 .400,00$. O valor máximo foi de $\mathrm{R} \$$ 18.215.676.000,00, que corresponde ao município de Vitória, para o ano de 2011 e, o valor mínimo foi de R $\$ 20.032 .500,00$, para o município de Divino de São Lourenço, ano de 2005. No que tange às operações de crédito (OPCRED), a média correspondeu à $R \$$ 138.149.200,00. O volume das operações de crédito diverge muito entre os municípios, 
sendo perceptível quando se observam os valores de máximo de $\mathrm{R} \$ 5.994 .328 .100,00$, e de mínimo de $\mathrm{R} \$$ 803.000,00, que representam os municípios de Vitória e Alegre, respectivamente. É oportuno salientar que o destaque de Vitória pode ser devido a este município ser a maior praça financeira do estado.

Tabela 2: Estatísticas Descritivas: todos os municípios

\begin{tabular}{l|c|c|c|c|c|c|c}
\hline \hline \multicolumn{1}{c|}{ Variável } & Média & Median & Des. & Máximo & Mínim & Assimetri & Curtos \\
\hline PIBTOTAL & 852.715, & 161.990, & $2.235 .197,0$ & 18.215 .676$, & 20.032, & 4,61 & 24,04 \\
\hline PIBAGRO & $24.489,7$ & $18.002,7$ & $26.528,5$ & $283.834,2$ & 895,2 & 4,18 & 25,99 \\
\hline PIBIND & 268.694, & $18.851,4$ & $729.316,05$ & $4.688 .564,3$ & 680,45 & 3,71 & 14,36 \\
\hline PIBSERV & 401.198, & $92.724,5$ & $1.049 .890,3$ & $7.983 .467,7$ & 14.129, & 4,77 & 25,10 \\
\hline OPCRED & 138.149, & $34.677,7$ & $534.465,7$ & $5.994 .328,1$ & 803,0 & 8,19 & 73,29 \\
\hline POP & $46.117,7$ & $18.497,0$ & $85.918,5$ & $485.376,0$ & $4.471,0$ & 3,43 & 14,23 \\
\hline IFDMGERA & 0,70 & 0,70 & 0,08 & 0,88 & 0,48 & $-0,19$ & 2,61 \\
\hline IFDMEMPR & 0,58 & 0,56 & 0,13 & 0,91 & 0,24 & 0,29 & 2,80 \\
\hline IFDMEDUC & 0,76 & 0,77 & 0,09 & 0,94 & 0,45 & $-0,74$ & 3,21 \\
\hline IFDMSAUD & 0,76 & 0,78 & 0,11 & 0,97 & 0,35 & $-0,69$ & 3,01 \\
\hline \hline
\end{tabular}

Fonte: elaborado pelos autores a partir dos dados da pesquisa.

Cabe dizer que, pelas estatísticas da Tabela 2, existe uma grande heterogeneidade entre os municípios do Espírito Santo no que se refere às variáveis em estudo, uma vez que houve grande disparidade entre os valores de máximo e de mínimo, com desvios-padrão significativamente elevados. Destaca-se que as disparidades municipais são aprofundadas quando se comparam os municípios da Região da Grande Vitória (RGV) - Cariacica, Serra, Vila Velha e Vitória -, com os demais municípios do estado, especialmente do interior. É importante dizer que, em geral, as variáveis apresentaram assimetria positiva e alto valor para a curtose, sendo que os coeficientes assimetria e curtose foram diferentes daqueles da distribuição normal padrão, que são zero e três, respectivamente.

Analisando a situação da distribuição da oferta de crédito nos municípios capixabas, pode-se observar na Figura 1 que, no ano de 2015, a mesma esteve concentrada na RGV (Cariacica, Serra, Vila Velha e Vitória), sendo que somente Vitória concentrou 36,23\% do volume de crédito. Em termos de volume de crédito, destacam-se também: i) Cachoeiro de Itapemirim, que pode vista como uma praça financeira regional, sendo que o município é um polo em sua microrregião (Central); ii) o mesmo ocorre com Colatina, polo regional e praça financeira da microrregião Centro-Oeste, sendo que, além dos agentes bancários tradicionais, o município possui uma agência do Banco do Nordeste do Brasil; e, iii) Linhares e São Matheus, que são destaques nas microrregiões Rio Doce e Nordeste, também possuindo agências do Banco do Nordeste do Brasil. Destaca-se, também, que todos os municípios nomeados na Figura 1 possuíam, em 2015, população maior que 100 mil habitantes, o que também contribui para o maior volume de crédito. 


\section{Figura 1: Participação (\%) dos Municípios nas Operações de Crédito do Espírito Santo (2015)}

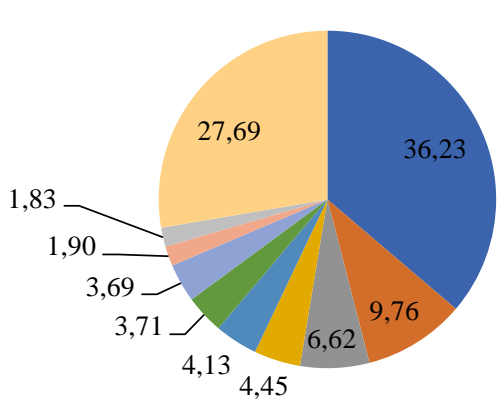

Fonte: elaborado pelos autores a partir dos dados da pesquisa.
- Vitória

- Vila Velha

- Serra

Cachoeiro de Itapemirim

- Cariacica

- Colatina

- Linhares

- São Mateus

A fim de aprofundar as análises sobre a oferta de crédito nos municípios do Espírito Santo, por meio da Equação (5), adaptada de Araújo et al. (2010), é possível calcular o Índice de Concentração de Crédito (ICC) dos municípios do Espírito Santo. Aqui, valores maiores que um revelam que o saldo de operações de crédito de um município em específico $(m)$ foi superior à sua participação relativa no PIB estadual $(e)$. Neste caso, o município recebe um volume de crédito mais que proporcional à sua importância econômica na geração de produtos para o Espírito Santo. Caso o índice seja menor que um, o oposto é verdadeiro.

$$
I C C_{m, e}=\frac{\frac{\text { Saldo de Operações de crédito no município }}{\text { Saldo de Operações de crédito no estado }}}{\frac{P I B \text { município }}{\text { PIB estado }}} .
$$

As Figuras 2 e 3 mostram os resultados para os municípios que apresentaram ICC maior e menor que um, respectivamente, para o ano de 2015. Dos 78 municípios, 46 obtiveram índice maior que um, sendo que este grupo contemplou municípios como: Vitória, Colatina, Cachoeiro de Itapemirim, Guarapari, São Mateus e Vila Velha. Vale frisar que alguns municípios, como Guarapari, São Mateus e Vila Velha, apresentaram valores acima, mas muito próximos de um. Os municípios de Cariacica, Linhares e Serra permaneceram no grupo com índice menor que um. Ressalta-se que, no caso da RGV, o grande destaque foi o município de Vitória, que é a maior praça financeira do estado, concentrando o maior volume de crédito entre todos os municípios (Figura 1). Entretanto, esperavam-se valores maiores do índice para os municípios Serra e Cariacica, uma vez que estão entre os municípios que apresentaram maiores volumes de crédito para o ano de 2015. Não é objeto deste estudo, mas caberia uma análise mais profunda, a fim de verificar se a proximidade com Vitória supre a demanda por crédito desses municípios ou se o desenvolvimento financeiro dos mesmos é deficiente e precisa ser estimulado. No mais, conforme já destacado, para Linhares também se esperava um valor expressivo e maior que 
um, dado que é um polo regional e possui uma agência do Banco do Nordeste do Brasil, cabendo também uma pesquisa mais aprofundada.

Figura 2: Índice de Concentração de Crédito nos Municípios (maior que um), 2015

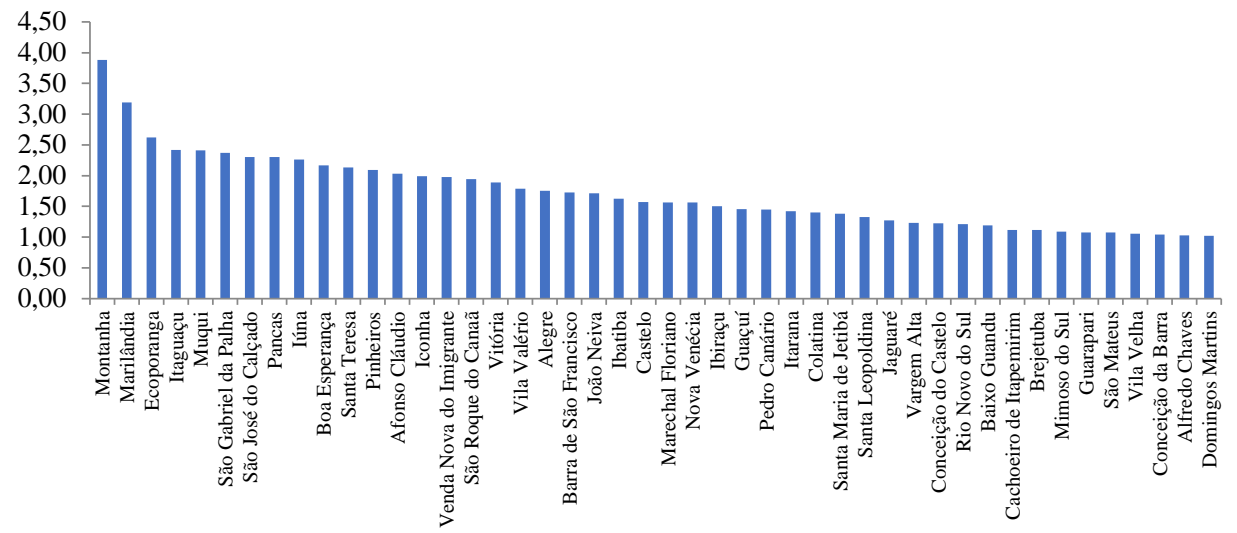

Fonte: elaborado pelos autores a partir dos dados da pesquisa.

Figura 3 - Índice de Concentração de Crédito nos Municípios (menor que um), 2015

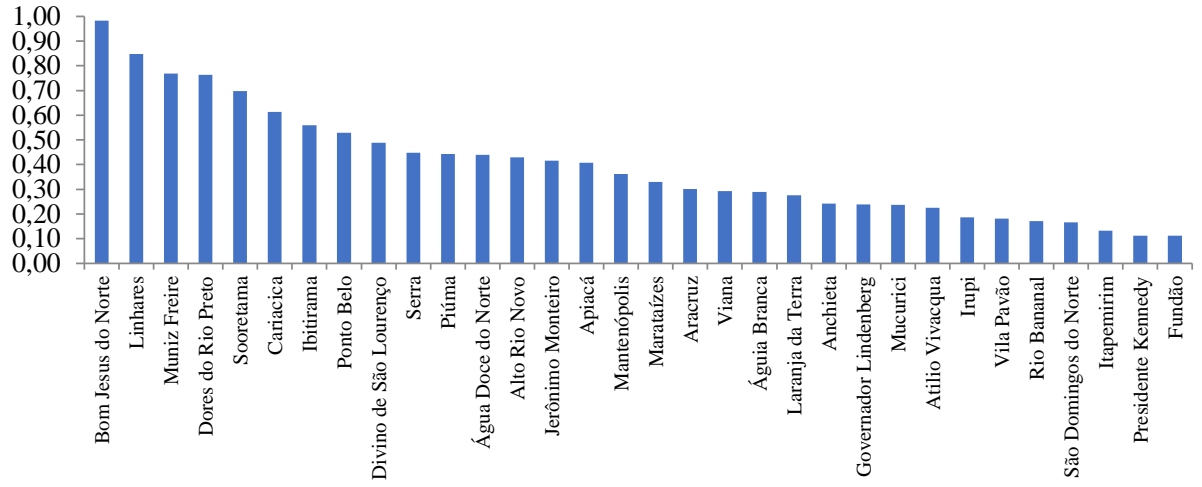

Fonte: elaborado pelos autores a partir dos dados da pesquisa.

\subsection{Estimativas Econométricas}

As estimativas econométricas relativas a todos os municípios podem ser observadas nas Tabelas 3, 4, 5 e 6. Para dar robustez às estimativas foram estimados cinco modelos, sendo adotadas proxies de indicadores socioeconômicos e demográficos como variáveis de controle nos Modelos 2, 3, 4 e 5. Em geral, as estimativas foram realizadas pelo modelo de efeitos fixos ${ }^{4}$ (EF, por meio de variáveis dummies, LSVD), sendo que as

\footnotetext{
${ }^{4}$ Somente na Tabela 4, Modelos 1, 4 e 5, o teste de Hausman indicou a utilização de efeitos aleatórios. Vale mencionar que o coeficiente de determinação e o coeficiente de determinação ajustado para modelos de efeitos
} 
regressões foram estimadas na forma duplo-logarítmica. A escolha do modelo para cada regressão foi feita por meio do teste de Hausman (1978), considerando um nível de significância de $10 \%{ }^{5}$. Cabe destacar que, em relação às estimativas por efeitos fixos, quando as estimativas por MQO resultaram em resíduos que não seguiam distribuição normal, adotou-se o método de MQG. Wooldridge (2002) salienta que o método de MQG diminui os impactos da não normalidade dos resíduos sobre o modelo estimado e, neste caso, é possível aceitar a não normalidade dos resíduos, mesmo ela persistindo após a estimação da regressão desejada. No mais, para todas as regressões, com o intuito de obter erros-padrão robustos, foi utilizado o método de covariância do coeficiente (coefficient covariance method) White Cross-Section.

\section{Tabela 3: Impacto das Operações de Crédito no LPIBTOTAL: todos os municípios}

\begin{tabular}{l|c|c|c|c|c}
\hline \hline Variáveis & Modelo 1 & Modelo2 & Modelo 3 & Modelo 4 & Modelo 5 \\
\hline Constante & $8,836 * *$ & $7,562^{* * *}$ & $6,425^{* * *}$ & $7,413^{* * *}$ & $7,977 * * *$ \\
\hline L(OPCRED) & $0,335^{* * *}$ & $0,327^{* * *}$ & $0,240^{* * *}$ & $0,198^{* * *}$ & $0,207 * * *$ \\
\hline L(POP) & - & $0,135^{\mathrm{ns}}$ & $0,372^{* * *}$ & $0,316^{* *}$ & $0,251^{*}$ \\
\hline L(IFDMGERAL) & - & - & $0,947 * * *$ & - & - \\
\hline L(IFDMEMPR) & - & - & - & $0,139 * * *$ & $0,123 * * *$ \\
\hline L(IFDMEDUC) & - & - & - & $0,582^{* * *}$ & $0,577 * * *$ \\
\hline L(IFDMSAUDE) & - & - & - & $0,307 * * *$ & $0,280 * * *$ \\
\hline DUMMY & - & - & - & - & $-0,072 * * *$ \\
\hline $\mathrm{N}$ & 858 & 858 & 858 & 858 & 858 \\
\hline R ajustado & 0,996 & 0,996 & 0,997 & 0,997 & 0,996 \\
\hline $\begin{array}{l}\text { Teste F (igualdade } \\
\text { de interceptos) }\end{array}$ & $140,22[0,00]$ & $77,01[0,00]$ & $74,69[0,00]$ & $74,60[0,00]$ & $74,60[0,00]$ \\
\hline \begin{tabular}{l} 
Teste de Hausman \\
\hline \hline
\end{tabular} & $44,70[0,00]$ & $22,14[0,00]$ & $14,77[0,00]$ & $32,70[0,00]$ & $32,70[0,00]$ \\
\hline
\end{tabular}

Fonte: elaborado pelos autores a partir dos dados da pesquisa.

Notas: 1) *** Significativo a 1\%; ** Significativo a 5\%; * Significativo a $10 \%$; ${ }^{\text {ns }}$ Não significativo a $10 \% ; 2$ )

Entre colchetes encontram-se os valores-p das estatísticas de teste; 3) L = Indica que as variáveis estão expressas em logaritmos; e, 4) Estimativas por efeitos fixos, com o método de covariância do coeficiente (coefficient covariance method) White Cross-Section.

Na Tabela 3 são apresentados os resultados quando considerada como variável dependente o PIBTOTAL. O coeficiente da variável operações de crédito revelou-se

fixos do tipo $L S D V$ tende a ser elevado, devido ao grande número de variáveis explicativas, advindas da inclusão de variáveis dummies para diferenciar os indivíduos. Assim, não se pode comparar o coeficiente de determinação e o coeficiente de determinação ajustado do modelo LSDV (com dummies) com os respetivos coeficientes do modelo de efeitos aleatórios. Para maiores detalhes, consultar Greene (2012).

${ }^{5} \mathrm{O}$ teste baseia-se na ideia de que, sob a hipótese de não correlação, os estimadores de efeitos fixos (EF) e de efeitos aleatórios (EA) são consistentes, mas EF é ineficiente, enquanto, sob a hipótese alternativa, o EF é consistente, mas o EA não (GREENE, 2012). Os resultados dos testes realizados podem ser consultados junto ao autor. 
positivo e significativo em todos os modelos estimativos. Vale destacar que, ao incluir as variáveis de controle, os impactos da oferta de crédito sobre o PIB foram menores, mas ainda positivos e significativos. Tomando como referência o Modelo 5, nota-se que um aumento de $1 \%$ das operações de crédito no período corrente levou à um crescimento de $0,207 \%$ no PIB total. Cabe observar que os coeficientes das variáveis de controle POP, IFDMGERAL, IFDMEMPR, IFDMEDUC e IFDMSAUDE foram, na maioria dos modelos, significativos e positivos. A variável DUMMY no Modelo 5 apresentou coeficiente significativo e negativo, conforme o esperado.

Em relação às estimativas da Tabela 4, estas tomam como variável dependente o PIB agropecuário (PIBAGRO). O coeficiente da variável OPCRED foi significativo a 1\% em todos os modelos. Considerando o Modelo 5 como exemplo, nota-se que um aumento de $1 \%$ na oferta de crédito acarretou um crescimento de $0,13 \%$ no PIB agropecuário, no período em estudo. Isso deveria ser visto com atenção pelos formuladores de políticas públicas, dado que o PIB agropecuário ainda possui grande representatividade no PIB total dos municípios capixabas, especialmente os do interior do estado.

Tabela 4: Impacto das Operações de Crédito no LPIBAGRO: todos os municípios

\begin{tabular}{l|c|c|c|c|c}
\hline \hline Variáveis & Modelo 1 & Modelo2 & Modelo 3 & Modelo 4 & Modelo 5 \\
\hline Constante & $7,407 * * *$ & $4,383^{* * *}$ & $3,679^{\text {ns }}$ & $7,778^{* * *}$ & $8,340^{* * *}$ \\
\hline L(OPCRED) & $0,227 * * *$ & $0,218^{* * *}$ & $0,184^{* * *}$ & $0,122^{* * *}$ & $0,130^{* * *}$ \\
\hline L(POP) & - & $0,311^{\mathrm{ns}}$ & $0,430^{*}$ & $0,091^{\mathrm{ns}}$ & $0,028^{\mathrm{ns}}$ \\
\hline L(IFDMGERAL) & - & - & $0,376^{* *}$ & - & - \\
\hline L(IFDMEMPR) & - & - & - & $0,020^{\mathrm{ns}}$ & $-0,006^{\mathrm{ns}}$ \\
\hline L(IFDMEDUC) & - & - & - & $0,460^{* *}$ & $0,448^{* * *}$ \\
\hline L(IFDMSAUDE) & - & - & - & $0,291^{* * *}$ & $0,278^{* * *}$ \\
\hline DUMMY & - & - & - & - & $-0,158$ \\
\hline $\mathrm{N}$ & 858 & 858 & 858 & 858 & 858 \\
\hline $\mathrm{R}^{2}$ ajustado & 0,278 & 0,968 & 0,969 & 0,310 & 0,346 \\
\hline $\begin{array}{l}\text { Teste F (igualdade } \\
\text { de interceptos) }\end{array}$ & $162,5[0,00]$ & $161,0[0,00]$ & $164,7[0,00]$ & $165,3[0,00]$ & $165,3[0,00]$ \\
\hline Teste de Hausman & $1,27[0,26]$ & $7,20[0,03]$ & $10,34[0,02]$ & $7,13[0,21]$ & $7,13[0,21]$ \\
\hline \hline
\end{tabular}

Fonte: elaborado pelos autores a partir dos dados da pesquisa.

Notas: 1) *** Significativo a $1 \%$; ** Significativo a $5 \%$; * Significativo a $10 \%$; ns Não significativo a $10 \% ; 2$ ) Entre colchetes encontram-se os valores-p das estatísticas de teste; 3) L = Indica que as variáveis estão expressas em logaritmos; e, 4) Estimativas por efeitos aleatórios, com o método de covariância do coeficiente (coefficient covariance method) White Cross-Section. Exceto para os Modelos 2 e 3 que adotaram efeitos fixos (EF).

A Tabela 5 demonstra os resultados considerando como variável dependente o PIB industrial (PIBIND). Observa-se que o coeficiente da variável OPCRED foi significativo em todas as regressões. No caso do Modelo 5, por exemplo, a elevação de $1 \%$ das operações de crédito levou a um aumento de $0,223 \%$ do PIB do setor industrial. Vale dizer que o 
setor industrial é o segundo em participação média no PIB total do estado, alavancado pela metalurgia, pela extração de minerais metálicos e pela extração de petróleo e gás natural. Dessa forma, dada a importância do setor para o Espírito Santo, os governos estadual e municipal podem adotar medidas para que as operações de crédito contribuam cada vez mais para o seu desenvolvimento, tanto nos municípios que já possuem o setor fortalecido como para aqueles que não o possuem, visando ao desenvolvimento do interior capixaba.

Tabela 5: Impacto das Operações de Crédito no LPIBIND: todos os municípios

\begin{tabular}{l|c|c|c|c|c}
\hline \hline Variáveis & Modelo 1 & Modelo2 & Modelo 3 & Modelo 4 & Modelo 5 \\
\hline Constante & $6,308^{* * *}$ & $6,221^{*}$ & $5,430^{* *}$ & $5,723^{* *}$ & $7,293^{* * *}$ \\
\hline L(OPCRED) & $0,389^{* * *}$ & $0,384^{* * *}$ & $0,245^{* * *}$ & $0,223^{* * *}$ & $0,261^{* * *}$ \\
\hline L(POP) & - & $0,013^{\mathrm{ns}}$ & $0,291^{\mathrm{ns}}$ & $0,272^{\mathrm{ns}}$ & $0,081^{\mathrm{ns}}$ \\
\hline L(IFDMGERAL) & - & - & $1,526^{* * *}$ & - & - \\
\hline L(IFDMEMPR) & - & - & - & $0,297 * * *$ & $0,312^{* * *}$ \\
\hline L(IFDMEDUC) & - & - & - & $0,683 * * *$ & $0,586^{* *}$ \\
\hline L(IFDMSAUDE) & - & - & - & $0,435^{* * *}$ & $0,450 * * *$ \\
\hline DUMMY & - & - & - & - & $-0,142$ \\
\hline $\mathrm{N}$ & 858 & 858 & 858 & 858 & 858 \\
\hline $\mathrm{R}^{2}$ ajustado & 0,983 & 0,983 & 0,987 & 0,987 & 0,986 \\
\hline $\begin{array}{l}\text { Teste F (igualdade } \\
\text { de interceptos) }\end{array}$ & $99,07[0,00]$ & $76,46[0,00]$ & $69,78[0,00]$ & $68,33[0,00]$ & $68,33[0,00]$ \\
\hline Teste de Hausman & $17,48[0,00]$ & $17,38[0,00]$ & $15,63[0,00]$ & $25,86[0,00]$ & $25,86[0,00]$ \\
\hline \hline
\end{tabular}

Fonte: elaborado pelos autores a partir dos dados da pesquisa.

Nota: 1$) * * *$ Significativo a $1 \%$; ** Significativo a 5\%; * Significativo a $10 \%$; ns Não significativo a $10 \% ; 2$ )

Entre colchetes encontram-se os valores-p das estatísticas de teste; 3 ) $\mathrm{L}=$ Indica que as variáveis estão expressas em logaritmos; e, 4) Estimativas por efeitos fixos, com o método de covariância do coeficiente (coefficient covariance method) White Cross-Section.

Os resultados da Tabela 6 referem-se às estimativas quando o PIB comercial e de serviços (PIBSERV) é considerado como variável dependente. O coeficiente da variável operações de crédito revelou-se significativo e com expressivos efeitos positivos sobre PIBSERV. Levando-se em conta o Modelo 5, um aumento das operações de crédito de $1 \%$ gerou uma elevação de $0,195 \%$ no PIBSERV. O setor de comércio e serviços é o que mais contribui para o PIB total dos municípios do Espírito Santo (em média 60\% do PIB total, em 2015). Em municípios como Água doce do Norte, Alto Rio Novo, Apiacá, Guaçuí, Guarapari, Ibatiba, Iúna, Gerônimo Monteiro, Mantenópolis, Muqui, São Mateus, entre outros, o PIB do setor chegou a representar, em média, 70\% do PIB total, em 2015. Dessa forma, políticas públicas que facilitem a tomada de crédito podem levar a bons resultados econômicos para os municípios capixabas.

Como já mencionado, nove municípios do Espírito Santo (Cachoeiro de Itapemirim, Cariacica, Colatina, Guarapari, Linhares, São Mateus, Serra, Vila Velha e Vitória) concentraram 72,31\% do volume de crédito ofertado no estado, em 2015, sendo que estes 
municípios possuíam mais de 100 mil habitantes. Retirando-os da amostra, o restante (69 munícipios) respondia por, somente, 27,69\% da oferta de crédito, no ano de 2015. Assim, para complementar e dar robustez às análises, além das regressões para todos os municípios (78), estimativas para dois blocos de municípios foram realizadas: i) municípios com maior volume de crédito (mais de 100 mil habitantes; Tabela 7); e, ii) municípios com menor volume de crédito (menos de 100 mil habitantes; Tabela 8). Exceto para o PIBIND (Tabela 7) e o PIBAGRO (Tabela 8), em que se adotou o modelo efeitos aleatórios (EA), as demais estimativas foram realizadas pelo modelo de efeitos fixos (EF, por meio de variáveis dummies, LSVD), sendo que as regressões foram estimadas na forma duplo-logarítmica. A escolha do modelo para cada regressão foi feita por meio do teste de Hausman (1978), considerando um nível de significância de $10 \%$.

Tabela 6: Impacto das Operações de Crédito no LPIBSERV: todos os municípios

\begin{tabular}{l|c|c|c|c|c}
\hline \hline Variáveis & Modelo 1 & Modelo2 & Modelo 3 & Modelo 4 & Modelo 5 \\
\hline Constante & $8,223 * * *$ & $5,400 * * *$ & $4,139 * * *$ & $5,090 * * *$ & $5,522^{* * *}$ \\
\hline L(OPCRED) & $0,339 * * *$ & $0,320 * * *$ & $0,258 * * *$ & $0,194 * * *$ & $0,195 * * *$ \\
\hline L(POP) & - & $0,302 * * *$ & $0,517 * * *$ & $0,491 * * *$ & $0,446 * * *$ \\
\hline L(IFDMGERAL) & - & - & $0,727 * * *$ & - & - \\
\hline L(IFDMEMPR) & - & - & - & $0,079 * * *$ & $0,074 * * *$ \\
\hline L(IFDMEDUC) & - & - & - & $0,628 * * *$ & $0,622 * * *$ \\
\hline L(IFDMSAUDE) & - & - & - & $0,233 * * *$ & $0,234 * * *$ \\
\hline DUMMY & - & - & - & - & $-0,022 * * *$ \\
\hline $\mathrm{N}$ & 858 & 858 & 858 & 858 & 858 \\
\hline R ajustado & 0,998 & 0,998 & 0,998 & 0,998 & 0,998 \\
\hline $\begin{array}{l}\text { Teste F (igualdade de } \\
\text { interceptos) }\end{array}$ & $213,12[0,00]$ & $79,79[0,00]$ & $82,01[0,00]$ & $85,36[0,00]$ & $85,36[0,00]$ \\
\hline Teste de Hausman & $56,86[0,00]$ & $20,52[0,00]$ & $10,62[0,01]$ & $25,42[0,00]$ & $25,42[0,00]$ \\
\hline \hline
\end{tabular}

Fonte: elaborado pelos autores a partir dos dados da pesquisa.

Notas: 1) ${ }^{* * *}$ Significativo a $1 \% ;{ }^{\text {ns }}$ Não significativo a $10 \% ; 2$ ) Entre colchetes encontram-se os valores-p das estatísticas de teste; 3) L = Indica que as variáveis estão expressas em logaritmos; e, 4) Estimativas por efeitos fixos, com o método de covariância do coeficiente (coefficient covariance method) White CrossSection.

Quanto aos resultados da Tabela 7, ressalta-se que, dado o menor número de observações (99), as estimativas podem ter algumas imprecisões, a saber: i) como os intervalos de confiança tendem a ser mais amplos, isso pode ter levado à insignificância estatística de alguns coeficientes estimados; os sinais de alguns coeficientes estimados foram contrários aos esperados, no que se refere às variáveis socioeconômicas e demográficas; dada a menor dispersão dos dados, alguns coeficientes podem ter sido superestimados; entre outras. Mesmo assim, em todos os casos, a variável operações de crédito apresentou coeficiente positivo e significativo. Já os resultados da Tabela 8 revelam coeficientes significativos para as operações de crédito em todas as estimativas. 
Tabela 7: Impacto das Operações de Crédito no PIB: municípios com maior volume de crédito

\begin{tabular}{l|c|c|c|c}
\hline \hline Variáveis & LPIBTOTAL & LPIBAGRO & LPIBIND & LPIBSERV \\
\hline Constante & $2,930^{*}$ & $0,959^{\mathrm{ns}}$ & $-9,913^{* *}$ & $-1,541^{\mathrm{ns}}$ \\
\hline $\mathrm{L}(\mathrm{OPCRED})$ & $0,253^{* * *}$ & $0,365^{* * *}$ & $0,339^{* * *}$ & $0,237^{* * *}$ \\
\hline $\mathrm{L}(\mathrm{POP})$ & $0,025^{\mathrm{ns}}$ & $-0,461^{\mathrm{ns}}$ & $0,799^{*}$ & $0,369^{* * *}$ \\
\hline $\mathrm{L}(\mathrm{IFDMEMPR})$ & $0,288^{* * *}$ & $-0,263^{* *}$ & $1,322^{* * *}$ & $0,137^{* *}$ \\
\hline $\mathrm{L}(\mathrm{IFDMEDUC})$ & $0,324^{* * *}$ & $-0,708^{\mathrm{ns}}$ & $-1,463^{* * *}$ & $0,575^{* * *}$ \\
\hline $\mathrm{L}(\mathrm{IFDMSAUDE})$ & $0,347^{*}$ & $-0,365^{\mathrm{ns}}$ & $0,997^{* * *}$ & $0,163^{\mathrm{ns}}$ \\
\hline DUMMY & $0,012^{\mathrm{ns}}$ & $-0,109^{* * *}$ & $-0,065^{* * *}$ & $0,047^{* * *}$ \\
\hline $\mathrm{N}$ & 99 & 99 & 99 & 99 \\
\hline $\mathrm{R} \mathbf{R}^{2}$ ajustado & 0,996 & 0,986 & 0,382 & 0,998 \\
\hline $\begin{array}{l}\text { Teste F (igualdade de } \\
\text { interceptos) }\end{array}$ & $66,53[0,000]$ & $106,61[0,000]$ & $47,02[0,000]$ & $58,65[0,000]$ \\
\hline Teste de Hausman & $20,84[0,000]$ & $39,12[0,000]$ & $5,31[0,379]$ & $34,63[0,000]$ \\
\hline \hline
\end{tabular}

Fonte: elaborado pelos autores a partir dos dados da pesquisa.

Notas: 1) *** Significativo a $1 \%$; ** Significativo a $5 \%$; $*$ Significativo a $10 \%$; ns Não significativo a $10 \% ; 2$ )

Entre colchetes encontram-se os valores-p das estatísticas de teste; 3$) \mathrm{L}=$ Indica que as variáveis estão expressas em logaritmos; e, 4) Estimativas por efeitos fixos, com o método de covariância do coeficiente (coefficient covariance method) White Cross-Section. Exceto para o PIBIND que adotou efeitos aleatórios.

Tabela 8: Impacto das operações de crédito no PIB: municípios com menor volume de crédito

\begin{tabular}{l|c|c|c|c}
\hline \hline Variáveis & LPIBTOTAL & LPIBAGRO & LPIBIND & LPIBSERV \\
\hline Constante & $6,864^{* * *}$ & $5.612^{* * *}$ & $4,765^{*}$ & $5,532^{* * *}$ \\
\hline $\mathrm{L}(\mathrm{OPCRED})$ & $0,208^{* * *}$ & $0,120^{* * *}$ & $0,272^{* * *}$ & $0,189^{* * *}$ \\
\hline $\mathrm{L}(\mathrm{POP})$ & $0,341^{* *}$ & $0,326^{*}$ & $0,300^{\mathrm{ns}}$ & $0,436^{* * *}$ \\
\hline $\mathrm{L}(\mathrm{IFDMEMPR})$ & $0,111^{* * *}$ & $0,028^{\mathrm{ns}}$ & $0,287^{* * *}$ & $0,068^{* * *}$ \\
\hline $\mathrm{L}(\mathrm{IFDMEDUC})$ & $0,593^{* * *}$ & $0,453^{* * *}$ & $0,699^{* * *}$ & $0,614^{* * *}$ \\
\hline $\mathrm{L}(\mathrm{IFDMSAUDE})$ & $0,238^{* * *}$ & $0,282^{* * *}$ & $0,307^{* * *}$ & $0,247^{* * *}$ \\
\hline $\mathrm{DUMMY}$ & $-0,087^{* * *}$ & $-0,148^{* * *}$ & $-0,150^{* * *}$ & $-0,037^{* * *}$ \\
\hline $\mathrm{N}$ & 759 & 759 & 759 & 759 \\
\hline $\mathrm{R}^{2}$ ajustado & 0,988 & 0,330 & 0,974 & 0,991 \\
\hline $\begin{array}{l}\text { Teste } \mathrm{F} \text { (igualdade de } \\
\text { interceptos) }\end{array}$ & $72,18[0,000]$ & $105,28[0,000]$ & $69,07[0,000]$ & $81,60[0,000]$ \\
\hline Teste de Hausman & $28,32[0,000]$ & $6,50[0,270]$ & $23,17[0,000]$ & $19,27[0,000]$ \\
\hline \hline
\end{tabular}

Fonte: elaborado pelos autores a partir dos dados da pesquisa.

Notas: 1) *** Significativo a $1 \%$; ** Significativo a $5 \%$; $*$ Significativo a $10 \%$; ns Não significativo a $10 \% ; 2$ )

Entre colchetes encontram-se os valores-p das estatísticas de teste; 3) L = Indica que as variáveis estão

expressas em logaritmos; e, 4) Estimativas por efeitos fixos, com o método de covariância do coeficiente (coefficient covariance method) White Cross-Section. Exceto para o PIBAGRO que adotou efeitos aleatórios. 
Por fim, para fins de robustez dos resultados, na Tabela 9 são apresentadas algumas estimativas para o PIB total (PIBTOTAL) ${ }^{6}$ - levando-se em conta todos os municípios (78) -, considerando a abordagem de painel dinâmico, por meio do método de momentos generalizados (MMG), que lida com a possível endogenia das variáveis explicativas. Cabe dizer que a estimação de dados em painel dinâmico por MMG remete-se aos trabalhos de Arellano e Bond (1991), Arellano e Bover (1995) e Blundell e Bover (1998). Especificamente em relação a este trabalho, adotou-se o método de momentos generalizados em diferenças (MMG-DIF) (ARELLANO; BOND, 1991). Isso porque, nas estimações com MMG system, em função da dimensão cross-section restrita, principalmente para modelos menos parcimoniosos, ocorreram problemas de excesso de instrumentos ou de não validade do conjunto de instrumentos, mesmo após a utilização do comando collapse, do pacote plm do $R$ project.

Em relação aos resultados da Tabela 9, destaca-se que, para todas as regressões estimadas, o teste de Sargan revelou que os instrumentos adotados foram válidos. No que tange aos coeficientes estimados para a variável operações de crédito (OPCRED), nota-se que houve uma redução na magnitude dos mesmos, quando comparados aos coeficientes da Tabela 3 (modelo estático). No entanto, os efeitos do crédito sobre o PIB total permaneceram positivos e significativos, corroborando os resultados da Tabela 3.

\section{Tabela 9: Impacto das Operações de Crédito no LPIBTOTAL Usando Painel Dinâmico: todos os municípios}

\begin{tabular}{l|c|c|c|c}
\hline \hline Variáveis & Modelo 1 & Modelo2 & Modelo 3 & Modelo 4 \\
\hline L(PIBTOTAL(-1)) & $0,480 * * *$ & $0,439 * * *$ & $0,407 * * *$ & $0,352 * * *$ \\
\hline L(OPCRED) & $0,165 * * *$ & $0,201 * * *$ & $0,100 * * *$ & $0,107 * * *$ \\
\hline L(POP) & - & $-0,335 * * *$ & $0,133 * * *$ & $-0,135 * * *$ \\
\hline L(IFDMGERAL) & - & - & $0,903 * * *$ & - \\
\hline L(IFDMEMPR) & - & - & - & $0,168 * * *$ \\
\hline L(IFDMEDUC) & - & - & - & $0,455^{* * *}$ \\
\hline L(IFDMSAUDE) & - & - & - & $0,302 * * *$ \\
\hline DUMMY & - & - & - & $-0,113 * * *$ \\
\hline Teste Sargan - Valor-p & 0,121 & 0,267 & 0,283 & 0,163 \\
\hline \hline
\end{tabular}

Fonte: elaborado pelos autores a partir dos dados da pesquisa.

Nota:1) *** Significativo a 1\%; e, 2) Utilizou-se o MMG-DIF (MMG em diferenças), pelo método two-step.

Dessa forma, independente do modelo estimado, no período em análise, as estimativas evidenciam que a oferta de crédito pode ser vista como um dos impulsionadores do crescimento econômico dos municípios do Espírito Santo, um estado periférico, em que os setores terciário e industrial são os mais relevantes. Os resultados deste trabalho são similares a estudos anteriores realizados no Brasil, em que houve uma relação positiva entre

\footnotetext{
${ }^{6}$ Os resultados referentes aos PIB's setoriais podem ser consultados junto aos autores.
} 
desenvolvimento do sistema financeiro e o crescimento econômico, como por exemplo: i) em nível nacional - Marques Jr. e Porto Jr. (2004); ii) em nível estadual - Monte e Távora Júnior (2000) e Missio, Jayme Jr e Oliveira (2015); e, iii) em nível municipal - Kroth e Dias (2006).

\section{Conclusão}

O objetivo deste trabalho foi analisar os efeitos do crédito sobre crescimento econômico dos municípios do Espírito Santo, no período de 2005 a 2015, utilizando a metodologia de dados em painel. As análises foram feitas considerando o PIB total e o PIB dos setores: agropecuário, industrial e comercial e de serviços. No mais, além das estimações para o total de municípios (78), as estimativas foram realizadas para duas subamostras, a saber: i) municípios com mais de 100 mil habitantes, que concentram a grande parte da oferta de crédito; e, ii) municípios com menos de 100 mil habitantes, que representaram somente 27,69\% da oferta de crédito dos municípios capixabas, em 2015.

Primeiramente ressalta-se que, analisando a situação da distribuição da oferta de crédito nos municípios capixabas, no ano de 2015 , a mesma concentrou-se $(72,31 \%$ da oferta) em nove municípios (Cachoeiro de Itapemirim, Cariacica, Colatina, Guarapari, Linhares, São Mateus, Serra, Vila Velha e Vitória), com destaque para a RGV, sendo que, somente Vitória, maior praça financeira do Espírito Santo, representou 36,23\% do volume de crédito. Além disso, de acordo com o ICC, nos municípios capixabas, em geral, o saldo de operações de crédito em relação à oferta de crédito total do estado é relativamente pequeno, quando comparado à participação relativa destes municípios, em termos de PIB, no PIB estadual. Não é objeto deste estudo, mas caberia uma análise mais profunda, a fim de verificar se, por exemplo, para os municípios da RGV, a proximidade com Vitória supre a demanda por crédito ou se o desenvolvimento financeiro dos mesmos é deficiente e precisa ser estimulado. Para outros municípios como Linhares, também caberiam análises mais profundas, visto que o município é um polo regional e possui uma agência do Banco do Nordeste do Brasil.

Do ponto de vista econométrico, observa-se que, mesmo i) adotando indicadores socioeconômicos e demográficos como variáveis de controle, ii) estimando modelos para o PIB total e para o PIB dos setores agropecuário, industrial e de comércio e serviços, iii) realizando estimações para o total de municípios (78) e para duas subamostras, e iv) adotando a abordagem de painel dinâmico, a oferta de crédito parece contribuir para o crescimento econômico dos municípios do Espírito Santo. Assim, políticas públicas que facilitem a tomada de crédito podem levar a bons resultados econômicos para os municípios capixabas. Neste caso, dada à concentração de crédito existente em poucos municípios, sendo estes em geral mais desenvolvidos, a atenção dos governos estadual e municipal para os municípios do interior do Estado seria um ponto importante tem termos de política de interiorização do desenvolvimento estadual.

Por fim, cabe destacar alguns aspectos institucionais do sistema financeiro capixaba que merecem destaque, ficando a sugestão de estudos futuros mais aprofundados 
sobre os mesmos, a saber: i) a presença do Banco do Estado do Espírito Santo (Banestes), controlado pelo governo estadual; ii) o Espírito Santo possui um banco de desenvolvimento estadual, o Banco de Desenvolvimento do Espírito Santo (Bandes); e, iii) alguns municípios localizados ao norte do Espírito Santo pertencem à área de abrangência da Superintendência de Desenvolvimento do Nordeste (Sudene), possuindo agências Banco do Nordeste do Brasil (BNB).

\section{Agradecimentos}

Os autores gostariam de agradecer ao Conselho Nacional de Desenvolvimento Científico e Tecnológico - CNPq (concessão no 406319/2018-9) e à Fundação de Amparo à Pesquisa e Inovação do Espírito Santo - FAPES pelo apoio financeiro.

\section{Referências}

AMADO, A. A questão regional e o sistema financeiro no Brasil: uma interpretação póskeynesiana. Estudos Econômicos, v. 27, n. 3, p. 417-440, 1997.

ARAUJO, V. L.; PIRES, M. J. S.; SILVA, M. F.; CASTRO, D. A. Padrão de atuação das Instituições Financeiras de Desenvolvimento (IFD's) brasileiras: balanços e perspectivas. IPEA/ABDE, 2010. Mimeografado.

ARELLANO, M; BOND, S. Some tests of specification for panel data: Monte Carlo evidence and an application to employment equations. Review of Economic Studies, v. 58, p. 277-297, 1991.

ARELLANO, M; BOVER, O. Another look at the instrumental variable estimation of error-components models. Journal of Econometrics, v. 68, p. 29-52, 1995.

DOI: https://doi.org/10.1016/0304-4076(94)01642-D

ASTERIOU, D.; PRICE, S. Financial development and economic growth: time series evidence for the case of UK. Ekonomia, v. 4, n. 2, p. 122-141, 2000.

BENCIVENGA, V.; SMITH, B. Financial intermediation and endogenous growth.

Review of Economic Studies, v. 58, n. 2, p. 195-209, 1991.

DOI: https://doi.org/10.2307/2297964

BENCIVENGA, V.; SMITH, B.; STARR, R. Equity markets, transactions costs, and capital accumulation: an illustration. The World Bank Economic Review, v. 10, n. 2, p. 241-265, 1996

BLACKBURN, K.; HUNG, V. A Theory of growth, financial development and trade. Economica, v. 65, n. 257, p. 107-124, 1998.

DOI: https://doi.org/10.1111/1468-0335.00116 
BLUNDELL, R.; BOND, S. Initial conditional and moment restrictions in dynamic panel data models. Journal of Econometrics, v. 87, n. 1, p. 115-143, 1998.

CAÇADOR, S. B.; GRASSI, R. A. Olhar crítico sobre o desempenho recente da economia capixaba: uma análise a partir da literatura de desenvolvimento regional e de indicadores de inovação. Revista Econômica do Nordeste, v. 40, n. 3, p 453-480, 2009.

CAÇADOR, S. B.; MONTE, E. Z. Crédito e crescimento econômico: o caso dos municípios do Espírito Santo. In: MAGALHÃES, M. A.; TOSCANO, V. N. (Org.). A Economia do Espírito Santo: novas visões. Vitória: CORECON-ES, 2012.

DEIDDA, L. G. Interaction between economic and financial development. Journal of Monetary Economics, v. 53, p. 233-248, 2006.

DOI: https://doi.org/10.1016/j.jmoneco.2005.03.007

DEMETRIADES, P.; HUSSEIN, K. Does financial development cause economic growth? Time-series evidence from 16 countries. Journal of Development Economics, v. 51, n. 2, p. 387-411, 1996.

DOI: https://doi.org/10.1016/S0304-3878(96)00421-X

DOW, S. C. The regional composition of the money multiplier process. Scottish Journal of Political Economy, v. 19, n. 1, p. 22-44, 1982.

DOI: https://doi.org/10.1111/j.1467-9485.1982.tb00434.x

DRUMMOND, I.; AGUIAR, A. Desenvolvimento do sistema financeiro e crescimento econômico. Cadernos do Mercado de Valores Mobiliários, n. 18, p. 22-46, 2004.

GELB, A. H. Financial Policies, Growth, and Efficiency. World Bank Working Paper, WPS 202, 1989.

GOLDSMITH, R. W. Financial Structure and Development. New Haven: Yale University, 1969.

GRANGER, C. W. J.; HUANG, L. Notes on the Evolution of Panel Models. Working Paper. University of California, San Diego, 1997.

GREENWOOD, J.; JOVANOVIC, B. Financial Development, Growth, and the Distribution of Income. Journal of Political Economy, v. 98, n. 5, p. 1076-1107, 1990.

GREENE, W. H. Econometrics Analysis. 7 ed. New Jersey: Pearson, 2012.

GUISO, L.; SAPIENZA, P.; ZINGALES, L. Does local financial development matter? The Quarterly Journal of Economics, v. 119, v. 3, p. 929-969, 2004.

HASSAN, M. K.; SANCHEZ, B.; YU, J-S. Financial development and economic growth: new evidence from panel data. The Quarterly Review of Economics and Finance, v. 51, n. 1, p. 88-104, 2011.

DOI: https://doi.org/10.1016/j.qref.2010.09.001 
HAUSMAN, J. A. Specification tests in econometrics. Econometrica, v. 46, n. 6, p. 1251-1271, 1978.

HOLTZ-EAKIN, D.; NEWEY, W.; ROSEN, H. Estimating vector autoregressions with panel data. Econometrica, v. 56, n. 6, p. 1371-95, 1988.

DOI: https://doi.org/10.2307/1913103

KEYNES, M. J. The General Theory of Employment, Interest and Money. London: Macmlllan, 1936.

KING, R.; LEVINE, R. Finance and growth: Schumpeter might be right. Quarterly Journal of Economics, v. 108, n. 3, p. 717-737, 1993a.

KING, R.; LEVINE, R. Finance, entrepreneurship, and growth: theory and evidence. Journal of Monetary Economics, v. 32, n. 3, p. 513-542, 1993 b.

DOI: https://doi.org/10.1016/0304-3932(93)90028-E

KROTH, D.; DIAS, J. A contribuição do crédito bancário e do capital humano no crescimento econômico dos municípios brasileiros: uma avaliação em painéis de dados dinâmicos. In: ENCONTRO NACIONAL DE ECONOMIA, 2006, Salvador. Anais... Associação Nacional dos Centros de Pós-Graduação em Economia (ANPEC), 2006.

JACQUES, E. R.; GONÇALVES, F. O. Cooperativas de crédito no Brasil: evolução e impacto sobre a renda dos municípios brasileiros. Economia e Sociedade, v. 25, n. 2, p. 489-509, 2016. DOI: https://doi.org/10.1590/1982-3533.2016v25n2art8

LAWRENCE, P. Finance and development: why should causation matter? Journal of International Development, v. 18, p. 997-1016, 2006.

DOI: https://doi.org/10.1002/jid.1333

LEVINE, R. Law, finance, and economic growth. Journal of Financial Intermediation, v. 8, n. 1-2, p. 8-35, 1999.

DOI: https://doi.org/10.1006/jfin.1998.0255

LEVINE, R.; ZERVOS, S. Stock markets, banks, and economic growth. American Economic Review, v. 88, n. 3, p. 537-558, 1998.

MCKINNON, R. I. Money and Capital in Economic Development. Washington: The Brookings Institution, 1973.

MARQUES JR, T. E.; PORTO JR, S. Desenvolvimento Financeiro e Crescimento Econômico no Brasil: uma avaliação econométrica. PPGE/UFRGS. Trabalho para Discussão, $\mathrm{n}^{\circ} .11,2004$.

MATOS, O. C. Desenvolvimento do Sistema Financeiro e Crescimento Econômico no Brasil: evidências de causalidade. Brasília, Banco Central do Brasil, 2002, (Texto para Discussão $n^{\circ} 49$ ). 
MISSIO, F. J.; JAYME JR., F. G.; OLIVEIRA, A. M. H. C. Desenvolvimento financeiro e crescimento econômico: teoria e evidência empírica para os estados brasileiros (19952004). Análise Econômica, v. 33, n. 63, p. 191-227, 2015.

MODIGLIANI, F.; MILLER, M. H. The cost of capital, corporation finance and the theory of investment. American Economic Review, v. 48, p. 261-97, 1958.

MONTE, P. A.; TÁVORA JÚNIOR, J. L. Fontes de financiamento do Nordeste e o produto interno bruto da região. Revista Econômica do Nordeste, v. 3, n. especial, p.676-695, 2000.

ÖNDER, Z.; ÖZYILDIRIM, S. Banks, regional development disparity and growth: evidence from turkey. Cambridge Journal of Economics, v. 34, n. 6, p. 975-1000, 2009.

PAGANO, M. Financial markets and growth: an overview. European Economic Review, v. 37, p. 613-622, 1993.

DOI: https://doi.org/10.1016/0014-2921(93)90051-B

REICHSTUL, D.; LIMA, G. T. Causalidade entre crédito bancário e nível de atividade econômica na Região Metropolitana de São Paulo: algumas evidências empíricas.

Revista Estudos Econômicos, v. 36, n. 4, p. 779-801, 2006.

ROCHA, B. P.; NAKANE, M. I. Sistema financeiro e desenvolvimento econômico: evidências de causalidade em um painel para o Brasil. In: ENCONTRO NACIONAL DE ECONOMIA, 2007, Recife. Anais... Recife: Associação Nacional dos Centros de PósGraduação em Economia (ANPEC), 2007.

ROMERO, J. P.; ÁVILA, J. L. T. Sistema financeiro e desenvolvimento regional: um estudo sobre o financiamento bancário da atividade industrial no Brasil. Revista Economia, v. 11, n. 1, p. 217-263, 2010.

ROUBINI, N.; SALA-I-MARTIN, X. Financial repression and economic growth. Journal of Development Economics, v. 39, p. 5-30, 1992.

DOI: https://doi.org/10.1016/0304-3878(92)90055-E

SAINT-PAUL, G. Technological choice, financial markets and economic development. European Economic Review, v. 36, n. 4, p. 763-781, 1992.

DOI: https://doi.org/10.1016/0014-2921(92)90056-3

SCHUMPETER, J. A. The Theory of Economic Development: an inquiry into profits, capital, credit, interest, and the business cycle. Cambridge, MA: Harvard University Press 1911.

SHAW, E. S. Financial Deepning in Economic Development. New York: Oxford University Press, 1973.

STOCK, J. H.; WATSON, M. W. Econometria. São Paulo: Pearson (Addison Wesley), 2004. 
WOOLDRIDGE, J. M. Econometric Analysis of Cross Section and Panel Data.

Cambridge, Massachusetts: MIT Press, 2002.

ZARA, T. M. Desenvolvimento Financeiro, Crescimento e Desigualdade nos Estados Brasileiros. 54 f. 2006. Dissertação (Mestrado em Teoria Econômica) - Departamento de Economia, Faculdade de Economia, Administração e Contabilidade, Universidade de São Paulo, São Paulo, 2006. 